\title{
The Study of the Unusual Development of the Super Tropical Storms Surrounding Indonesia Maritime Continent Area In March 2018
}

\author{
Paulus Agus Winarso* \\ Indonesia State College Meteorology Climatology and Geophysic, Indonesia
}

Received:

*Corresponding author: Paulus Agus Winarso, Indonesia State College Meteorology Climatology and Geophysic, Indonesia

\section{Short Communication}

Based on the operational notes in relation with the tropical cyclones or storms development over Indonesia Maritime Continent area, it can be stated that surrounding the area to be easily developed with the highest frequency of occurrence over Northwest Pacific Ocean. Besides in this area, there was the area of the South China Sea and North Indian ocean to have the potential development of the tropical storm, where they generally develop starting the middle up to the end of the year. In other words, most of the Northern Hemisphere area of Indonesia Maritime Continent would be period activities of the tropical storm. Reversal condition over Southern Hemisphere of Indonesia Maritime Continent during the end of the year up to the beginning of the year would be period tropical storm activities.

On March 2018, there was the unusual development of the super tropical storms in both areas of Southern and Northern Hemispheres. Where over the Southern area had developed the super tropical storm of the so-called "Marcus" with activitiesperiod middle up to the end of March 2018 and over Northern area developed the super tropical storm of the so-called "Jelawat" with activity period starting the end of March up to beginning April 2018. Those super tropical storms development of Indonesia Maritime Continent would be classified as unusual the super tropical storms, because these tropical storms fastly develop into severe storm with the maximum wind in the center up to 80 knots(to be classified Willy-Willy as the name super tropical cyclone over Northern Hemisphere of Indonesia Maritime Continent and Typhoon as the name super tropical cyclone over Southern Hemisphere. Another physical aspect with regard with the global scale of the atmospheric dynamic especially with existing some features from the meteorological disturbances in the global and regional scales. From observation in the global aspect of the tropical wave, pulse the Madden Julian Oscillation was weak. And from the global phenomena of the El Nino and La Nina episodes Information from World Meteorological Organization source, the global scale condition would be the normal condition. It could stated that during
March 2018 to be in the normal condition without any activities of the global weather disturbances. If it refers to the previous years especially last years both over those areas, there were only a few tropical cyclones development over both hemispheres surrounding Indonesia.

The last year of 2017 during tropical cyclone season over Northwest Pacific ocean, it seems that the number of the tropical cyclone development to be below normal of the growth of the tropical storm. Even over southern hemisphere area of Indonesia Maritime Continent, from operational meteorologist observed to be less development of the tropical storm during last 5 years. This aspect would be interested to be studied through analytic and descriptive with regard the atmospheric condition [1].

From the global point of view, it can be stated that the global climate and weather especially starting at the beginning of the years 2018 especially entering into second quarter 2018, some meteorological condition showed the unusual condition in term of the low surface air temperature observed in the lowest atmosphere. The condition of the winter season $2017 / 2018$ could be one of the unusual conditions with increasing the winter storm activities over Northern Hemisphere to affect aerodrome closed for certain airports in big cities of the United States of America and Canada in Northern America Continent, it could be over European Countries and North Asian Continent [2].

The freezing water Niagara for the first time during last 50 years could be the additional condition from coolest than normal and it might longer than usual based upon public information and collecting the global climatic chart from National Climate Centers under coordination from the World Meteorological Organization. If the condition winter season 2017/2018 compared with the previous condition especially in the 17 years or it could be longest than usual period, the winter season 2017/2018 could be worst condition and situation especially with winter storm occurrences over most northern hemisphere middle of March. Reversal 
condition over the southern hemisphere with summer season with few day occurrences of the heat wave over Australia continent last January 2018. In the next Figure 1, it would describe the global air temperature (in Kelvin or in Centigrade it should be subtracted 273) at the low level (about 1500 meters from Mean Sea Level) as follows [3].

\section{T0850 2.5X2.5 ACCESS OP. ANAL. $\quad$ (K) 201802010000201802280000}

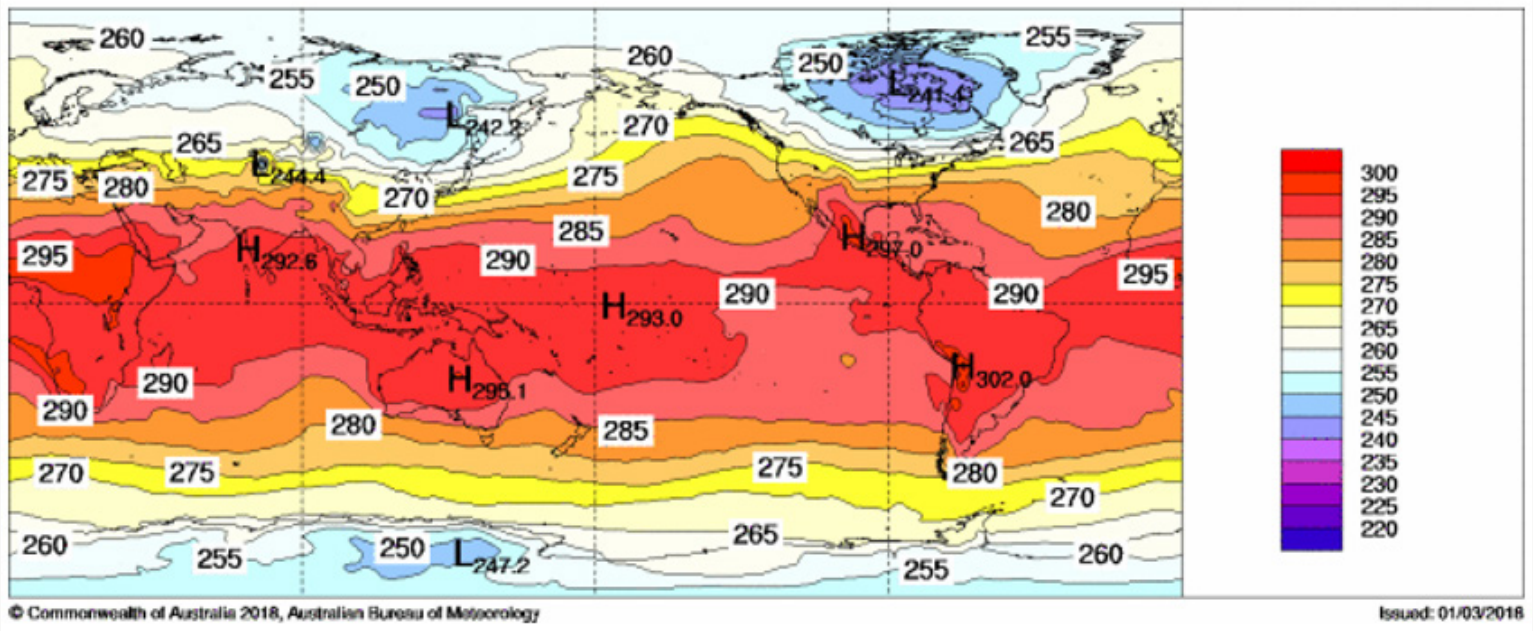

Figure 1: Global air temperature at March 2018 showed below 0 degrees Centigrade over the wider area of Northern Hemisphere (white - blue color) than Southern Hemisphere (Source: website Australian Burea of Meteorology [1].

\section{References}

1. Australian Bureau of Meteorology.
2. Indonesian Meteorological Climatological Agency.

3. NOAA.
CC (i) This work is licensed under Creative To Submit Your Article Click Here: Submit Article

DOI: $10.32474 /$ MAOPS.2018.02.000132

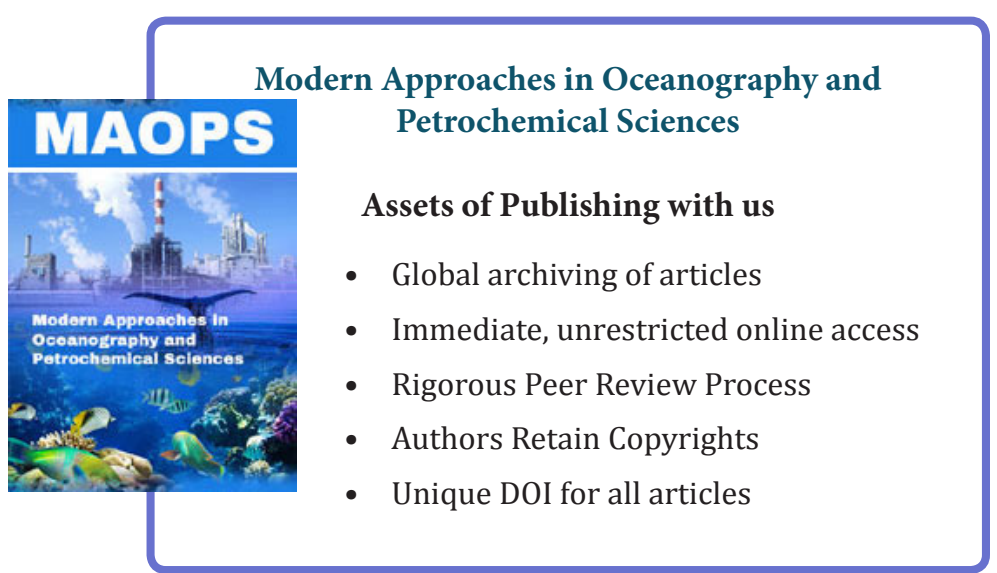

